\title{
Characteristics and Outcomes of Kidney Transplant Recipients with a Functioning Graft for More than 25 Years
}

\author{
Sandesh Parajuli ${ }^{\mathrm{a}}$ Didier A. Mandelbrot ${ }^{\mathrm{a}}$ Fahad Aziz $^{\mathrm{a}}$ Neetika Garg ${ }^{\mathrm{a}}$ \\ Brenda Muth $^{a}$ Maha Mohamed $^{a}$ Michael J. Armbrust ${ }^{a}$ Brad C. Astor ${ }^{a} b$ \\ Arjang Djamali ${ }^{\mathrm{a}, \mathrm{c}}$
}

${ }^{a}$ Division of Nephrology, Department of Medicine, University of Wisconsin School of Medicine and Public Health, Madison, WI, USA; ${ }^{b}$ Department of Population Health Sciences, University of Wisconsin School of Medicine and Public Health, Madison, WI, USA; ' Division of Transplant Surgery, University of Wisconsin School of Medicine and Public Health, Madison, WI, USA

\section{Keywords}

Kidney transplant $\cdot$ Survival $\cdot$ Complications $\cdot$ Cardiovascular disease $\cdot$ Infections $\cdot$ Malignancy

\begin{abstract}
Background: Information regarding the clinical characteristics and outcomes of kidney transplant recipients (KTRs) with $>25$ years of graft survival is limited. Methods: In this singlecenter observational study, we characterized KTRs transplanted between 1973 and 1992 with active follow-up as of July 31, 2017. Results: We identified 112 patients with $>25$ years of allograft function. The mean posttransplantation follow-up was $29.8 \pm 4.0$ years. Glomerulonephritis was the most common cause of end-stage renal disease (ESRD) (52\%). The majority received live donor transplants (66\%), including 25 patients (22\%) with human leukocyte antigenmatched kidneys. The incidence of biopsy-confirmed acute rejection was $21 \%$, ranging from 0 to 26 years post transplantation. Donor-specific antibodies (DSA) were checked in $80 \%$ of patients at a mean of $28.4 \pm 0.11$ years post transplantation. Of these, only $15 \%$ were positive. The incidence of ma-
\end{abstract}

\section{๑) 2018 S. Karger AG, Basel}

lignancy was $44 \%$, with nonmelanoma skin cancers being most common. The incidence of infectious complications was $77 \%$, mostly represented by urinary tract infections. At the time of last follow-up, $63 \%$ were on a calcineurin inhibitor (CNI)-free regimen, mean serum creatinine was $1.4 \pm 0.6$ $\mathrm{mg} / \mathrm{dL}$, and the prevalence of hypertension and dyslipidemia was 89 and $88 \%$, respectively. Conclusion: The majority of patients with a long-term functioning graft had glomerulonephritis as cause of ESRD, had received a live donor kidney, were on a CNI-free regimen, and had a low incidence of DSA and opportunistic infections. These characteristics define a unique group of patients requiring specific posttransplantation monitoring and management.

(c) 2018 S. Karger AG, Base

\section{Introduction}

Kidney transplantation is the best form of treatment for patients with end-stage renal disease (ESRD) of any cause. Kidney transplant recipients (KTRs) experience survival benefits in all age groups [1], have better health-
Sandesh Parajuli, MBBS

4175 UW Medical Foundation Centennial Building 1685 Highland Avenue

Madison, WI 53705 (USA)

E-Mail sparajuli@medicine.wisc.edu 
Table 1. Study population

\begin{tabular}{|c|c|}
\hline Number of patients & 112 \\
\hline Year of transplantation & 1973-1992 \\
\hline Mean age at transplantation, years & $34.0 \pm 8.9$ \\
\hline Male & $60(54 \%)$ \\
\hline $\begin{array}{l}\text { Race } \\
\text { Caucasian } \\
\text { African American } \\
\text { Other }\end{array}$ & $\begin{aligned} 107 & (96 \%) \\
& 2(2 \%) \\
& 3(2 \%)\end{aligned}$ \\
\hline $\begin{array}{l}\text { Cause of ESRD } \\
\text { Glomerulonephritis } \\
\text { Diabetes } \\
\text { Hypertension } \\
\text { Other }\end{array}$ & $\begin{aligned} 58 & (52 \%) \\
10 & (9 \%) \\
4 & (3 \%) \\
40 & (36 \%)\end{aligned}$ \\
\hline $\begin{array}{l}\text { Living donor transplant } \\
\text { Living related, biological } \\
\text { HLA-matched }\end{array}$ & $\begin{array}{l}74(66 \%) \\
68(61 \%) \\
25(22 \%)\end{array}$ \\
\hline $\begin{array}{l}\text { Previous KTRs } \\
\text { Second transplant recipients } \\
\text { Third transplant recipients }\end{array}$ & $\begin{array}{c}18(16 \%) \\
15(13 \%) \\
3(3 \%)\end{array}$ \\
\hline Preemptive KTRs & $45(40 \%)$ \\
\hline $\begin{array}{l}\text { HLA } 0 \text { mismatch } \\
\text { Deceased donor with HLA } 0 \text { mismatch }\end{array}$ & $\begin{array}{c}28(25 \%) \\
3(3 \%)\end{array}$ \\
\hline $\begin{array}{l}\text { Induction immunosuppressive medication } \\
\text { Depleting antibody (MALG, ATG, OKT3) } \\
\text { Unknown (depleting therapy or no } \\
\text { induction) }\end{array}$ & $\begin{array}{l}55(48 \%) \\
58(52 \%)\end{array}$ \\
\hline $\begin{array}{l}\text { Maintenance immunosuppression on discharg } \\
\text { Steroids } \\
\text { CsA/Neoral } \\
\text { Azathioprine } \\
\text { Mycophenolate }\end{array}$ & $\begin{aligned} 111 & (99 \%) \\
82 & (73 \%) \\
101 & (90 \%) \\
5 & (4 \%)\end{aligned}$ \\
\hline Mean hospital stay, days & $21.3 \pm 5.3(8-44)$ \\
\hline \multicolumn{2}{|c|}{$\begin{array}{l}\text { ATG, antithymocyte globulin; CsA, cyclosporine; ESRD, end- } \\
\text { stage renal disease; KTRs, kidney transplant recipients; MALG, } \\
\text { Minnesota antilymphocyte globulin. }\end{array}$} \\
\hline
\end{tabular}

related quality of life [2], and kidney transplantation is cost-effective compared to being on dialysis [3]. Deathcensored graft failure in kidney transplantation has improved significantly in the last $25-40$ years. The half-life of a standard criteria, deceased donor kidney in the United States has increased by almost 50\% from 10.6 years in 1989 to 15.5 years in 2005, and a similar pattern was seen with living donor transplants, mainly due to significant improvement in first-year graft survival [4]. Despite these advances, there has not been much improvement in longterm graft survival, and it is unlikely that a single kidney transplant will meet the need of lifelong renal replacement therapy, especially in younger KTRs [5]. The number of dialysis patients with a failed kidney transplant is increasing, and allograft failure among previous recipients of a kidney transplant is now the fourth leading cause of ESRD in the United States [6]. KTRs returning to dialysis have a significantly reduced survival rate compared to both the transplant-naïve dialysis population and those with functioning renal grafts [7-9]. Various factors, including age, disease recurrence, human leukocyte antigen (HLA) matching, delayed graft function, and various other donor-related factors that also influence graft survival influence the long-term outcome of kidney transplantation [10].

Despite these obstacles, there is a small group of patients with prolonged graft survival and good kidney function decades after transplantation. In this single-center observational study, we share our experience working with KTRs with a functional allograft for $>25$ years.

\section{Methods}

Study Population and Design

We analyzed data from KTRs in the Wisconsin Allograft Recipient Database. This single-center, retrospective observational study included KTRs at the University of Wisconsin, Madison who were actively followed at the University Hospital and Clinics and had a functional allograft for $>25$ years as of July 31,2017 . Patients transplanted at a different center but followed at our center, patients transplanted at our center but lost to follow-up, or those whose care was transferred to a different center were excluded from the study.

\section{The Kidney Transplantation Program of the University of}

Wisconsin

The University of Wisconsin has a history of kidney transplantation dating back $>50$ years [11]. More than 13,000 kidney transplantations have been performed here to date. The University of Wisconsin, Madison also has a high-volume outpatient clinic with $>1,000$ outpatient visits per month [12].

\section{Clinical Follow-Up and Monitoring}

We follow our KTRs at either the University Hospital or various outreach regional clinics at least once a year until graft failure or until the patient decides to transfer their care to a different transplantation center.

\section{Induction and Maintenance Immunosuppression}

Our induction and maintenance immunosuppression regimens have evolved with time. In the past, we used depleting agents in all KTRs unless they were receiving an HLA 0 mismatch kidney. In the early 1980s, our primary induction immunosuppressive 
Table 2. Posttransplantation complications

\begin{tabular}{lc}
\hline Patients with a kidney biopsy & $50(45 \%)$ \\
Mean interval from transplantation to biopsy, months & $108.2 \pm 132.5(0-356)$ \\
\hline Biopsy findings (mean interval from transplantation to biopsy findings in months) & $24(21 \%)(65.6 \pm 117.7)$ \\
Acute rejection & $14(13 \%)(52.0 \pm 88.3)$ \\
Calcineurin inhibitor toxicity & $3(3 \%)(57.3 \pm 49.9)$ \\
Disease recurrence & $49(44 \%)$ \\
\hline Patients with malignancy & 123 \\
Malignancies & $254.7 \pm 103.9(12-509)$ \\
Mean interval from transplantation to malignancy, months & $18(16 \%)(277.2 \pm 112.3)$ \\
\hline Type of primary malignancy (mean interval from transplantation to malignancy in months) \\
Squamous cell carcinoma skin & $19(17 \%)(214.9 \pm 86.2)$ \\
Basal cell carcinoma skin & $2(2 \%)(249 \pm 124.5)$ \\
Melanoma skin & $9(8 \%)(211.4 \pm 70.7)$ \\
Skin cancer of unknown cell type & $10(9 \%)(272.8 \pm 78.9)$ \\
Kidney/prostate/uroepithelium cancer & $86(77 \%)$ \\
\hline Patients with infection & 388 \\
Infections & $155.8 \pm 97.7(0.1-435)$ \\
Mean interval from transplantation to infection, months & \\
\hline Type of infection (mean interval from transplantation to infections in months) & $38(34 \%)(172.1 \pm 98.3)$ \\
Urinary tract infection & $11(10 \%)(22.8 \pm 66.4)$ \\
Cytomegalovirus & $18(16 \%)(137.8 \pm 78.2)$ \\
Pneumonia & $9(8 \%)(178.1 \pm 122.8)$ \\
Gastrointestinal &
\end{tabular}

medication was Minnesota antilymphocyte globulin (MALG); in the late 1980s and early 1990s, we began using OKT3, and later switched to antithymocyte globulin (ATG). Maintenance immunosuppression was similar in that we used cyclosporine, azathioprine, and steroids until the early 1990s and then switched to tacrolimus, mycophenolic acid, and prednisone. Most of our patients were maintained on triple immunosuppressive medications with tacrolimus or cyclosporine, mycophenolate mofetil or azathioprine, and prednisone as the standard of care. We did not routinely convert from cyclosporine to tacrolimus or mycophenolate to azathioprine unless there were any complications. Our longterm standard tacrolimus trough goal was $5-7 \mathrm{ng} / \mathrm{mL}$ and that of cyclosporine 50-100 ng/mL. Maintenance immunosuppression was adjusted, and some were discontinued based on transplantation provider discretion considering various factors, including immunological risk and complications.

\section{Results}

\section{Study Population (Table 1)}

A total of 2,749 KTRs were actively followed at our transplantation center as of July 31, 2017. Of that number, 112 (4\%) had had the same kidney allograft for $>25$ years. Patients were transplanted between 1973 and 1992, the mean age at the time of transplantation was $34.0 \pm 8.9$ years, 54\% were male, and the majority were Caucasian. Glomerulonephritis was the most common cause of ESRD (52\%), and only $9 \%$ had diabetes as a cause of ESRD. The majority were living KTRs and $40 \%$ were preemptive KTRs; 18 (16\%) had had previous kidney transplants, including $3(3 \%)$ recipients who had received their third transplant; 23 patients had been transplanted in or prior to 1983 (pre-cyclosporine era) and the rest after 1983.

\section{Transplantation-Specific Baseline Characteristics \\ (Table 1)}

A total of 28 patients (25\%) received HLA 0 mismatch kidneys, including 3 from deceased donors. MALG was used for induction immunosuppression in 33\% of the recipients, OKT3 in 11\%, and ATG in 4\%. We were not able to identify the induction immunosuppression in $52 \%$ of the patients, as it was not documented in the electronic medical records. However, based on our practice, we assume that the majority received a depleting agent with MALG or OKT3 unless they received an HLA 0 mismatch kidney. Ninety-nine percent of our patients were discharged home on steroids and $90 \%$ on azathioprine. The mean hospital stay post transplantation was $21.3 \pm 5.3$ days. 
Table 3. Findings at last follow-up

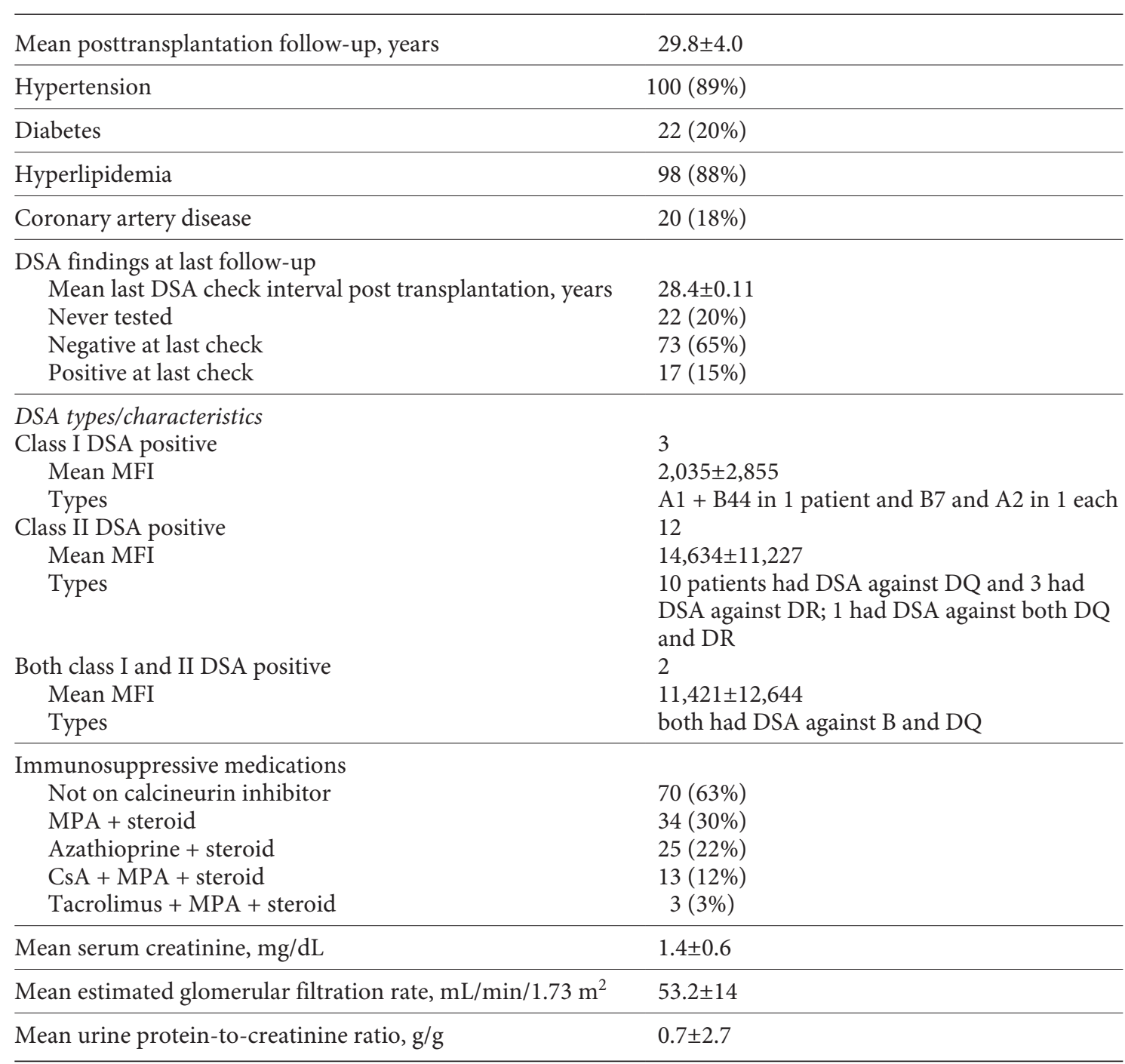

CsA, cyclosporine; DSA, donor-specific antibodies; MPA, mycophenolic acid.

\section{Posttransplantation Complications (Table 2)}

We examined three major posttransplantation complications: biopsy-proven rejection, malignancy, and infections. A total of $45 \%$ of the patients had 89 kidney biopsies, and $21 \%$ had features of acute rejection ranging from 0 to 312 months post transplantation. Similarly, $44 \%$ of the patients had 123 malignancies, with skin cancer being the most common. Other, less common, malignancies were lymphoma, breast cancer, and thyroid cancer. Seventy-seven percent had 388 infections, with urinary tract infections being the most common ones. Other less common infections were cellulitis, infective endocarditis, and sinusitis.

\section{Findings at Last Follow-Up (Table 3)}

At a mean posttransplantation follow-up of $29.8 \pm 4.0$ years, mean serum creatinine was $1.4 \pm 0.6 \mathrm{mg} / \mathrm{dL}$. The majority of patients had hypertension $(89 \%)$ and hyperlipidemia (88\%). At the last follow-up, 71 (63\%) were on a calcineurin inhibitor (CNI)-free regimen, $22 \%$ had diabetes, and $20 \%$ had coronary artery disease. Only $20 \%$ were never tested for donor-specific antibodies (DSA), and of those tested, 15\% were DSA positive, predominantly against DQ and DR. Out of the 71 patients on a CNI-free regimen, only $8(11 \%)$ had DSA at last followup. Anecdotally, 1 patient with a kidney from an identical twin was not on any immunosuppressive medication. Of 


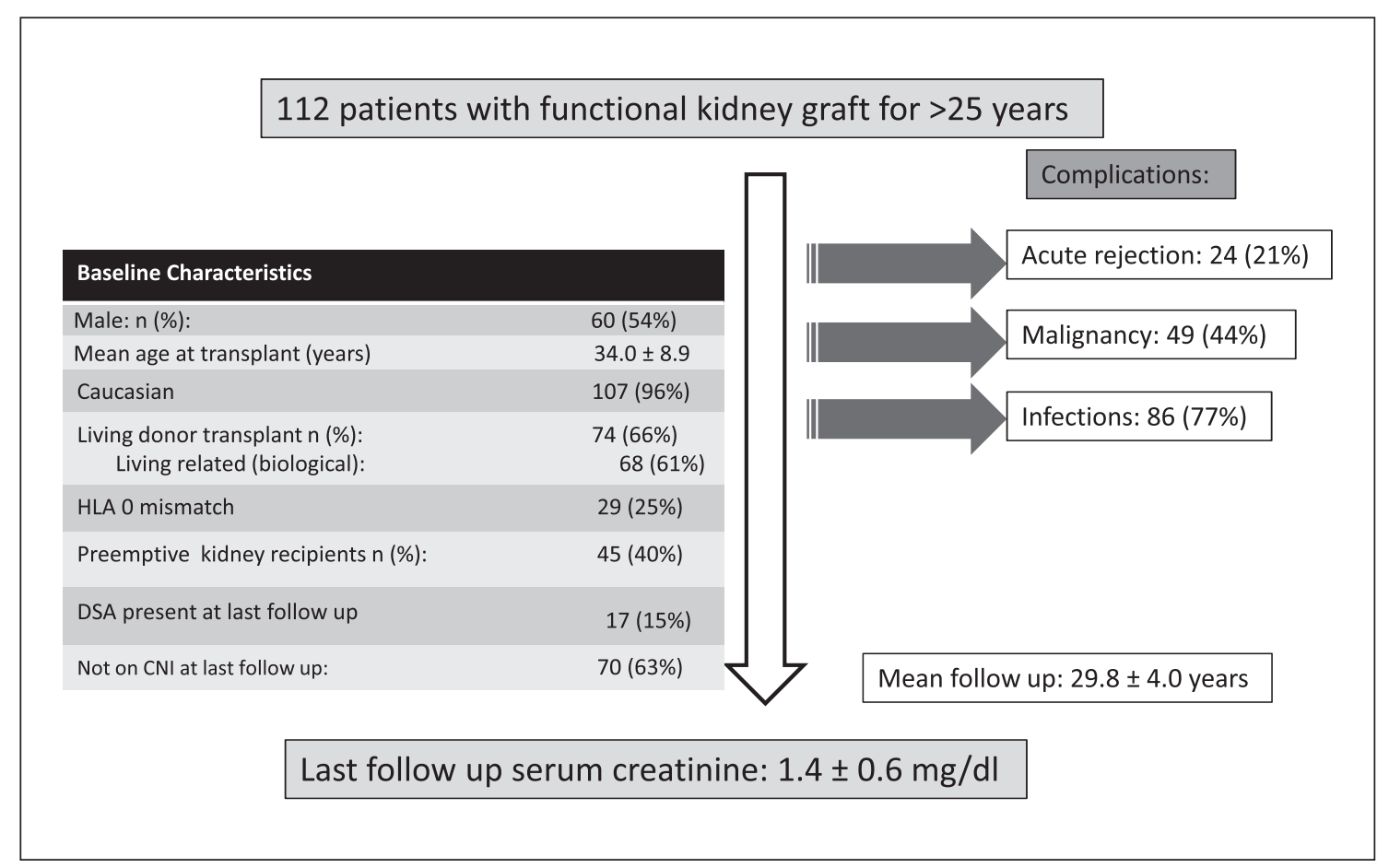

Fig. 1. Summary of patients with functional allografts for $>25$ years.

the 71 patients with a CNI-free regimen, the CNI was discontinued in 42 patients at an interval ranging from 1-24 years post transplantation due to complications or low immunological risk for rejection.

\section{Discussion}

In this large cohort of 112 KTRs with functional allograft for $>25$ years, we report some interesting findings as summarized in Figure 1. Twenty-one percent of the recipients had complications of rejection, $44 \%$ malignancy, and $77 \%$ infections, but patients maintained excellent graft function over this time. Hypertension and hyperlipidemia were prevalent, while diabetes and coronary artery disease were not, despite the fact that the patients had been KTRs for almost three decades.

There has been a significant improvement in the prevention of kidney rejection. Death with functional graft is the most common cause of graft failure, and cardiovascular disease (CVD), infections, and malignancies are the leading causes of death among KTRs [13]. CVD and mortality decrease after kidney transplantation compared to being on dialysis, but still remain more prevalent than in the general population. The risk of mortality is initially worse with kidney transplantation compared to dialysis, with a relative risk of 2.84; however, the risks are equal by 3-4 months post transplantation, and subsequently there are long-term survival benefits to the transplantation group [14]. Overall cardiovascular mortality is approximately two times higher in KTRs compared to the general population $[15,16]$. After CVD, infections are the second most common cause of death in KTRs. The risk of infection is significantly higher after kidney transplantation than in the general population and is a common cause of morbidity and mortality. Urinary tract infection is the most common bacterial infection requiring hospitalization in KTRs [17]. Another common complication in our KTRs is malignancy. The overall incidence of malignancy in KTRs is three to five times higher compared to the general population, with skin cancer being the most common cancer [3].

Kidney transplantation is not a cure for patients with ESRD, but it is a better form of treatment for ESRD than dialysis. Rejection, and predominately antibody-mediated rejection, is the most common cause of death-censored graft failure. Other common causes of graft failure include recurrence of the original diseases and BK virus nephropathy [6]. The majority of KTRs revert back to chronic kidney disease stage 2 or 3 after transplantation 
$[18,19]$. KTRs are a unique subgroup of patients with chronic kidney disease due to the presence of a single functioning kidney, the use of immunosuppressive medications, and the duration of disease [3].

In a study from Northern Ireland, of the 706 KTRs transplanted between 1968 and 1993, 117 (16\%) were still alive with a functional graft 20 years post transplantation [20]. The authors concluded that in these long-term kidney graft survivals, the focus of management should be on the prevention of cancers and CVD, as the prevalence was very high in these patients. In another study, the most common causes of death among KTRs 20 years after transplantation were CVD and malignancy [21]. As with our study, a higher incidence of cancer and CVD was found among 2,202 KTRs even 10 years after transplantation [22].

Despite these obstacles, some of the KTRs maintain excellent graft function. Kidney transplantation with functional graft for $>25$ years is a great success. As the prevalence of hypertension and dyslipidemia is significantly higher in our patient population, strategies for the optimum management of these cardiovascular risk factors may prevent cardiovascular events and prolong graft survival [23]. CVD is the most common cause of death in KTRs, despite recent efforts to increase the awareness of CVD in this patient population [24]. Hypertension with a blood pressure of $>140 / 90$ is prevalent in $>70 \%$ of transplant recipients [25]. There are no randomized controlled trials of antihypertensive drugs or optimal blood pressure goals in transplant recipients. However, pharmacological therapy along with nonpharmacological interventions, including weight reduction, exercise, and dietary sodium restriction, are recommended [24]. Similarly, dyslipidemia is also strongly associated with CVD. Dyslipidemia is linked with some immunosuppressive medications, including corticosteroids, CNIs, and sirolimus [24]. The Kidney Disease Outcomes Quality Initiative recommends that all adults and adolescents be tested for dyslipidemia on a regular basis and after the adjustment of immunosuppressive medications [26]. Attention to dyslipidemia is required as interventions for dyslipidemia have an impact on reducing cardiac events in clinical trials specific to the transplantation population [27].

Other common complications seen in our patient population were infections, particularly urinary tract infections. All urinary tract infections in KTRs are considered complicated, and thus standard treatment typically involves 7-14 days of antibiotic therapy [17]. It is recommended that KTRs should receive routine vaccines as per national and local guidelines, except for live attenuated vaccines [28]. Proper screening as well as early diagnosis and treatment may prolong patient survival as some of the clinical presentations may not be typical in immunosuppressed recipients.

Our observations have the limitations inherent to this type of study. As this was a single-center study, it may not be possible to generalize our results to other centers. There was not much diversity in the patients' race. Due to the nature of the study with historical data, among the recipients transplanted before 1992, some transplant-related information was missing. However, to our best knowledge, our study is the largest cohort of this type of study from a single center. Not only do our data provide some of the important aspects of patients with prolonged graft survival and associated complications to the providers, they also provide some encouragement and positive reinforcement to newly transplanted recipients and to patients on waiting lists.

In summary, the majority of patients with a long-term functioning graft had glomerulonephritis as cause of ESRD, received a live donor kidney, were on a CNI-free regimen, and had a low incidence of DSA and opportunistic infections. These characteristics define a unique group of patients requiring specific posttransplantation monitoring and management. As the number of KTRs with prolonged graft survival may be rising, health care providers should be aware of the management of complications associated with prolonged graft survival in this unique group of patients.

\section{Acknowledgments}

The authors are grateful to Ms. Dana Clark, MA for editorial assistance. They thank the medical and nursing staff who participated in the care of the patients in this study, and especially all patients within this study.

\section{Statement of Ethics}

All clinical and research activities were consistent with the principles of the Declaration of Helsinki. This study was approved by the Health Sciences Institutional Review Board at the University of Wisconsin. The study was of very minimal risk to the subjects, without any physical risk. The only potential risk was breach of confidentiality. We carefully reviewed our study procedures to ensure that the risk of breach of confidentiality was minimized as much as possible. For that reason, the research was conducted with waiver of informed consent per university policy. 


\section{Disclosure Statement}

The authors have no financial disclosures or conflicts of interest. There were no funding sources.

\section{Author Contributions}

S. Parajuli: concept, design, data collection, analysis, manuscript preparation. D.A. Mandelbrot: design, analysis, manuscript preparation, editing. F. Aziz: analysis, editing. N. Garg: analysis, editing. B. Muth: analysis, editing. M. Mohamed: analysis, editing. M.J. Armbrust: analysis, editing. B.C. Astor: analysis, editing. A. Djamali: original idea, concept, design, analysis, manuscript preparation, editing.

\section{References}

1 Pesavento TE: Kidney transplantation in the context of renal replacement therapy. Clin J Am Soc Nephrol 2009;4:2035-2039.

2 Fiebiger W, Mitterbauer C, Oberbauer R: Health-related quality of life outcomes after kidney transplantation. Health Qual Life Outcomes 2004;2:2.

3 Parajuli S, Clark DF, Djamali A: Is kidney transplantation a better state of CKD? Impact on diagnosis and management. Adv Chronic Kidney Dis 2016;23:287-294.

4 Lamb KE, Lodhi S, Meier-Kriesche HU: Long-term renal allograft survival in the United States: a critical reappraisal. Am J Transplant 2011;11:450-462.

5 Marcen R, Teruel JL: Patient outcomes after kidney allograft loss. Transplant Rev (Orlando) 2008;22:62-72.

6 Sellares J, de Freitas DG, Mengel M, Reeve J, Einecke G, Sis B, et al: Understanding the causes of kidney transplant failure: the dominant role of antibody-mediated rejection and nonadherence. Am J Transplant 2012;12: 388-399.

7 Perl J, Zhang J, Gillespie B, Wikstrom B, Fort J, Hasegawa T, et al: Reduced survival and quality of life following return to dialysis after transplant failure: the Dialysis Outcomes and Practice Patterns Study. Nephrol Dial Transplant 2012;27:4464-4472.

8 Rao PS, Schaubel DE, Jia X, Li S, Port FK, Saran R: Survival on dialysis post-kidney transplant failure: results from the Scientific Registry of Transplant Recipients. Am J Kidney Dis 2007;49:294-300

9 Kaplan B, Meier-Kriesche HU: Death after graft loss: an important late study endpoint in kidney transplantation. Am J Transplant 2002;2:970-974.
10 Legendre C, Canaud G, Martinez F: Factors influencing long-term outcome after kidney transplantation. Transpl Int 2014;27:19-27.

11 Sollinger HW, Becker YT, Burlingham W, D'Alessandro AM, Fernandez LA, Hullett D, et al: The history of the University of Wisconsin transplant program. Clin Transpl 2007: 271-287.

12 University of Wisconsin School of Medicine and Public Health: Kidney Transplant Program 2018. https://www.medicine.wisc.edu/ nephrology/renaltransplant.

13 El-Zoghby ZM, Stegall MD, Lager DJ, Kremers WK, Amer H, Gloor JM, et al: Identifying specific causes of kidney allograft loss. Am J Transplant 2009;9:527-535.

14 Wolfe RA, Ashby VB, Milford EL, Ojo AO, Ettenger RE, Agodoa LY, et al: Comparison of mortality in all patients on dialysis, patients on dialysis awaiting transplantation, and recipients of a first cadaveric transplant. N Engl J Med 1999;341:1725-1730.

15 Foley RN, Parfrey PS, Sarnak MJ: Clinical epidemiology of cardiovascular disease in chronic renal disease. Am J Kidney Dis 1998; 32(5 suppl 3):S112-S119.

16 Sarnak MJ, Levey AS: Cardiovascular disease and chronic renal disease: a new paradigm. Am J Kidney Dis 2000;35(4 suppl 1):S117S131.

17 Karuthu S, Blumberg EA: Common infections in kidney transplant recipients. Clin J Am Soc Nephrol 2012;7:2058-2070.

18 Marcen R, Pascual J, Tenorio M, Ocana EJ, Teruel JL, Villafruela JJ, et al: Chronic kidney disease in renal transplant recipients. Transplant Proc 2005;37:3718-3720.

19 Karthikeyan V, Karpinski J, Nair RC, Knoll G: The burden of chronic kidney disease in renal transplant recipients. Am J Transplant 2004; $4: 262-269$.
20 McCaughan JA, Courtney AE: The clinical course of kidney transplant recipients after 20 years of graft function. Am J Transplant 2015; 15:734-740.

21 Traynor C, Jenkinson A, Williams Y, O'Kelly $\mathrm{P}$, Hickey D, Denton M, et al: Twenty-year survivors of kidney transplantation. Am J Transplant 2012;12:3289-3295.

22 Matas AJ, Gillingham KJ, Humar A, Kandaswamy R, Sutherland DE, Payne WD, et al: 2202 kidney transplant recipients with 10 years of graft function: what happens next? Am J Transplant 2008;8:2410-2419.

23 Kasiske BL, Chakkera HA, Roel J: Explained and unexplained ischemic heart disease risk after renal transplantation. J Am Soc Nephrol 2000;11:1735-1743.

24 Gill JS: Cardiovascular disease in transplant recipients: current and future treatment strategies. Clin J Am Soc Nephrol 2008;3(suppl 2):S29-S37.

25 Kasiske BL, Anjum S, Shah R, Skogen J, Kandaswamy C, Danielson B, et al: Hypertension after kidney transplantation. Am J Kidney Dis 2004;43:1071-1081.

26 Kasiske BL; K/DOQI Dyslipidemia Work Group: Clinical practice guidelines for managing dyslipidemias in kidney transplant patients. Am J Transplant 2005;5:1576.

27 Agarwal A, Prasad GV: Post-transplant dyslipidemia: MECHANISMS, diagnosis and management. World J Transplant 2016;6: 125-134.

28 Kotton CN: Vaccinations in kidney transplant patients: searching for optimal protection. Clin J Am Soc Nephrol 2011;6:20992101. 